\title{
Reproductive Morbidity in Rajasthan: A Situational Analysis
}

\author{
Dr. Firdous Ansari
}

Ph.D. (Statistics), Singhania University, Jhunjhunu, Rajasthan, India

\begin{abstract}
Reproductive morbidity has its impact on women health and quality of life. In India and other developing countries sometimes pregnancy becomes dangerous due to the lack of medical care and ignorance as social and medical causes are associated with many pregnancy complications. In this study analyzed data is considered from Rajasthan Health Scenario 2000, Indian Institute of Health Management Research, Jaipur. The data is analyzed for Rajasthan, as well as for 41 districts of the state, using Statistical Package for Social Sciences. In the last section of the paper discussion is made.
\end{abstract}

Keywords: Reproductive morbidity, Pregnancy, Health Scenario of Rajasthan

\section{Introduction}

According to early studies, more than 54 million women suffer from diseases or complications during pregnancy and childbirth and more than one half million women die of causes related to pregnancy and childbirth each year[1][3].Various studies considered reproductive morbidity as inclusive of conditions of physical ill-health related to ,successful childbearing" and ,freedom from gynaecological disease and riske[4]-[7].According to world health organization (WHO)reproductive morbidity includes obstetric morbidity and it refers to ill health in relation to pregnancy and childbirth. Obstetric morbidity is defined as "morbidity in a woman who has been pregnant (regardless of site or duration of the pregnancy) resulting from any cause related to or aggravated by the pregnancy or its management but not from accidental or incidental causes" [8].

The overall prevalence of reproductive morbidity was found to be $46.3 \%$ : Gynaecological morbidity in $31.3 \%$ subjects, obstetric morbidity in $43.4 \%$ of the eligible women and contraceptive induced morbidity in $11.2 \%$ of the ever contraceptive users with $5 \%$ reporting more than one symptom [9].

Recent analyses show that maternal mortality declined by one-third between 1990 and 2008, although roughly 350,000 women in developing countries still die annually from pregnancy-related causes [10],[11]

In this paper an account of reproductive morbidity in the state of Rajasthan, with a comparison of the situation between its desert and non-desert districts is presented. This study considers four important parameters concerning with reproductive morbidity viz. percentage of eligible women who had pregnancy complications (PEWPC), percentage of eligible women who had delivery complications (PEWDC), percentage of eligible women who had post-delivery complications (PEWPC) and percentage of females having any symptoms of RTI/STI (PFRTI).

\section{Methodology}

The data considered, is taken from Rajasthan Health Scenario 2000, Indian Institute of Health Management Research, Jaipur (13).Considered parameters are analyzed for Rajasthan, as a whole and for 11 desert-districts and 30 non-desert districts of the state. The data is analyzed using Statistical Package for Social Sciences (SPSS) version16.0.Descriptive statistics, correlation coefficients of different parameters with Health Index (HI),t-test and multiple linear regression is computed. Significance of associations is also computed at $5 \%$ level of significance.

\section{Results}

\section{Rajasthan as a whole}

In Rajasthan, as a whole, eligible women having pregnancy complications were $57.1 \%$ When we analyzed it district wise we found that maximum women in this category are in Sawai Madhopur, Bharatpur, Ajmer, Chittorgarh and Banswara representing $66.5 \%, 63.8 \%, 63.8 \%, 61.3 \%$ and $59.4 \%$ respectively with minimum percentages $23.5,29$, $31.8,34.8$ and 40.3 in Hanumangarh, Churu, Dausa, Alwar and Jaipur respectively. The correlation coefficient between PCWPC and HI was found to be significantly negatively associated i.e. $-0.454(\mathrm{P}<0.05)$

As far as eligible women having pregnancy complications are concerned, in Bharatpur, Sawai Madhopur, Dholpur, Jhalawar and Barmer maximum number of women were reported, showing figure of $42.7 \%, 37.5 \%, 30.9 \%$ and $29.6 \%$ respectively. Minimum number of of women who had delivery complications were found in Churu (5.6\%), Rajsamand(6.2\%), Sikar and Pali with $6.7 \%$ and Hanumangarh (8.0\%).A negative correlation with $\mathrm{HI}$ is also found $(\mathrm{p}<0.05)$.

If we consider post-delivery complications, maximum percentages highlighted the values $63.2,51,48.4,44$ and 43 in Dausa, Jhalawar, Bharatpur, Dungarpur and Bhilwara respectively. Under the same head minimum percentages of women were 14,14.2, 15.2 and 15.3 belonging to Bundi, Jodhpur, Nagaur, Pali and Sikar respectively. A negative correlation of magnitude 0.341 was also turned out. 


\section{International Journal of Science and Research (IJSR) \\ ISSN (Online): 2319-7064 \\ Index Copernicus Value (2013): 6.14 | Impact Factor (2014): 5.611}

When we put our concentration on female having any symptoms of RTI/STI, Dausa, Bhilwara, Alwar, Bundi, and Bharatpur were observed representing $86.5 \%, 65.5 \%$, $61.8 \%, 60.2 \%$ and $56.2 \%$ respectively. In Sirohi, SawaiMadhopur, Jaisalmer, Chittorgarh and Hanumangarh , minimum percentage of females in such category disclosed were 22.5,27.6,28.1,29.9 and 30.9. Correlation between this factor and HI computed was, -0.407

\section{Desert versus Non Desert}

The women under PEWPC in desert were found at its peak was $58.7 \%$ in Jaisalmer with its subsequent values $56.6 \%, 53.9 \%, 49.3 \%$ and $49.2 \%$ in Sikar, Jhunjhunu, Bikaner and Nagaur respectively. If the least values are taken into consideration, it outcome Churu, Ganganagar, Jodhpur, Barmer and Pali with respective percentage 29, 45.3, 46.6, 46.7 and 47.3.

In desert Rajasthan, correlation between PEWPC and HI disclosed a contradiction showing non- significant negative association having a value $-0.044(\mathrm{p}>0.05)$

As far as PEWDC is taken into account in the same area i.e. desert part of Rajasthan, a non-significant positive association was observed with a figure $0.0457(\mathrm{p}=0.157)$. Maximum and minimum percentages of eligible women having delivery complications were 29.6(Barmer), 29(Ganganagar), 22.1(Bikaner), 16.1(Nagaur as well as Jaisalmer).

Similar to PEWDC, PEWPDC also turned out with a nonsignificant positive correlation having its value 0.192 $(\mathrm{p}=0.571)$. Most frequent occurrences of post-delivery complications were in Barmer, Jhunjhunu, Jaisalmer, Ganganagar, and Jalore with 39.2\%,33.3\%,30\%,24.8\%and $24.7 \%$ respectively with its minimum frequencies in Jodhpur, Pali, Nagaur, Sikar and Churu reflecting 14.2\%,15.2\% (in Pali and Nagaur), $15.3 \%$ and $16.3 \%$ respectively.

In case of females having any symptoms of RTI/STI,54.3\%,48.1\%,44.9\%,41.5\% and $37.6 \%$ were reported in Jalore, Barmer, Pali, Ganganagar, and Nagaur respectively. While Jaisalmer, Jodhpur, Sikar, Churu and Bikaner had lesser female having such symptoms. Under this head non-significant negative correlation was also computed.

Whereas in non-desert, Sawai Madhopur, Bharatpur, Ajmer, Chittorgarh and Banswara were reported as the states having a high number of females having pregnancy complications with $66.5 \%, 63.8 \%$ (for both Bharatpur and Ajmer) 61.3\% and $59.4 \%$ respectively. Hanumangarh, Dausa, Alwar, Jaipur and Kota had lowest numbers of such females. The percentages for these states were $23.5 \%, 31.8 \%, 34.8 \%$, $40.3 \%$ and $48.1 \%$ respectively. Correlation coefficient between PEWPC and HI was $-0.644(\mathrm{p}<0.01)$. Under the head PEWDC, maximum percentage was in Bharatpur (42.7\%), SawaiMadhopur (37.5\%), Dholpur (30.9\%), Jhalawar (30.4\%)and Banswars (27.3\%). Minimum delivery complications were observed in Rajsamand, Hanumangarh, Bhilwara, Kota and Bundi having the percentages 6.2,8.0,8.9, and 9.9 respectively. Kota and Bundi had the same percentages. In this case non-significant and negative correlation with a magnitude 0.410 was found $(p=0.081)$

In non-desert area of Rajasthan post-delivery complications were most frequent in Dausa, Jhalawar, Bharatpur, Dungarpur and Bhilwara. The respective percentages were 63.2,51,48.4,44 and 43.In Bundi, Kota, Hanumangarh, Sirohi and Chittorgarh, minimum percentages of $14,19.1,22.5,24$ and 28 of post- delivery complications were disclosed. In this case also a non-significant correlation coefficient -0.046 was computed $(\mathrm{p}=0.852)$.

In case of PFRTI, Dausa, Bhilwara, Alwar, Bundi and Bharatpur were top five states having females with any symptom of RTI/STI with $86.5 \%, 65.5 \%, 61.8 \%, 60.2 \%$ and $56.2 \%$ respectively. Under the same, states with minimum percentages were Sirohi (22.5\%), SawaiMadhopur (27.6\%), Chittorgarh (29.9\%), Hanumangarh (30.9\%)and Ajmer(34.3\%). The value of correlation coefficient was appeared to be $-0.152(p=0.547)$.

\section{Discussion}

In desert part of Rajasthan, Jaisalmer has $102 \%$ more pregnancy complications cases as compared to Churu. There were only $3.0 \%$ more cases of pregnancy complications than Rajasthan in Jaisalmer. As compared to Churu which has a minimum number under PEWDC, Barmer has around 430\% more cases with $55 \%$ extra cases than Rajasthan. Barmer is also leading under the category PEWPDC with $176 \%$ increased cases than Jodhpur.As compared to Rajasthan it is representing around $27 \%$ increment. Women with symptoms of RTI/STI are 93\% more in Jalore than Jaisalmer. As compared to Rajasthan, Jalore indicate $20 \%$ more cases of such type.

In non-desert, around 1835 more cases of PEWPC are there in SawaiMadhopur as compared to Hanumangarh. When a comparison is made with Rajasthan, $16 \%$ more cases in SawaiMadhopur are calculated. In Bharatpur, an increase of around $590 \%$ cases of delivery complications are caught as compared to Rajsamand. $124 \%$ additional cases in Bharatpur are observed as compared to the district Rajasthan. If we put our concentration on post-delivery complications in nondesert we find an addition of $351 \%$ in Dausa as compared to Bundi. Dausa has 104\% more post-delivery complications than Rajasthan.as far as females having symptoms of RTI/STI, there are $28.4 \%$ more women in Dausa as compare to Sirohi. In Dausa an increment of $92 \%$ cases is pinpointed.

The correlation coefficients are showing negative association in case of PEWPC and PFRTI with HI in desert whereas in case of PEWDC and PEWPDC with HI, it is showing positive but non-significant correlations. In nondesert all the heads considered are showing negative correlations.

The non-significant t-test (Table1)is an indication that climate conditions does not affect the reproductive health. Significant association between the predictors and $\mathrm{HI}$ in Table 2 confirms that complications during and after pregnancy have their impact on health. 


\section{International Journal of Science and Research (IJSR) \\ ISSN (Online): 2319-7064}

Index Copernicus Value (2013): 6.14 | Impact Factor (2014): 5.611

\section{Acknowledgement}

The author is extremely thankful to Prof.(Dr.) B.S. Rajpurohit, former Vice-Chancellor, Jai NarainVyas University(Jodhpur),Prof. (Dr.)P. K. Sharma(B),Prof. and
Head, Department of Chemistry, Jai Narain Vyas University and Dr. A.K. Dixit, Scientist ,Fee Desert Medicine Research Centre(ICMR), Jodhpur for their valuable suggestions and encouragement.

Table 1: Descriptive Statistics and t-test for Rajasthan

\begin{tabular}{|c|c|c|c|c|c|c|c|}
\hline Parameters & \multicolumn{2}{|c|}{ Rajasthan } & \multicolumn{2}{|c|}{ Desert Rajasthan } & \multicolumn{2}{|c|}{ Non-desert Rajasthan } & t-test (Desert Vs Non-desert) \\
\hline & Mean & SD & Mean & SD & Mean & SD & \\
\hline PEWPC & 50.83 & 10.55 & 48.28 & 7.73 & 52.3 & 11.83 & -0.97 \\
\hline PEWDC & 18.02 & 9.97 & 15.27 & 8.5 & 19.61 & 10.62 & -1.11 \\
\hline PEWPDC & 30.57 & 12.19 & 22.88 & 8.52 & 35.03 & 11.92 & -2.86 \\
\hline PFSRTI & 44.26 & 14.04 & 38.12 & 8.16 & 48.02 & 15.7 & -1.87 \\
\hline
\end{tabular}

Table 2: Analysis of Variance (ANOVA)

\begin{tabular}{|l|c|c|c|c|c|c|}
\hline \multicolumn{2}{|c|}{ Model } & Sum of Squares & Degrees of Freedom & Mean Square & F & Sig. \\
\hline \multirow{3}{*}{1} & Regression & .135 & 4 & .034 & 4.856 & $.005^{\text {a }}$ \\
\cline { 2 - 7 } & Residual & .167 & 24 & .007 & & \\
\cline { 2 - 7 } & Total & .303 & 28 & & & \\
\hline
\end{tabular}

\section{References}

[1] Holly E. Reed, Marjorie A. Koblinsky, and W. Henry Mosley "The Consequences of Maternal Morbidity and Maternal Mortality: Report of a Workshop. Committee on Population".National Research Council, 2000, Commission on Behavioral and Social Sciences and Education. Washington, DC: National Academy Press

[2] "Making Maternity Care More Accessible". 1993, Press Release No. 59. Geneva, Switzerland: World Health Organization.

[3] Estimates of Maternal Mortality: A New Approach by WHO and UNICEF. Geneva, Switzerland: World Health Organization 1996

[4] Evans, J., G. Lamb, N. Murthy and F. Shorter. "Women and children in poverty: reproductive health and child survival", 1987.Report to the trustees of the Ford Foundation for its mid-decade review of programs. New York: The Ford Foundation.

[5] Fathalla, M. "Research needs in human reproduction. Pp. 341-346 in Research in Human Reproduction: Biennial Report 1986-1987, ed. E. Diczfalusi, P.D. Griffin and J. Khanna. Geneva: World Health Organization". 1988

[6] Germaine, "A. Reproductive health and dignity: choices by third world women". Technical background paper for the International Conference on Better Health for Women and Children through Family Planning, Nairobi.1987.

[7] Zurayk, H. "A framework of ideas for development of a research agenda for the working group on reproductive health". Paper presented at First Meeting of Working Groups of The Population Council Special Program of Research and Technical Consultation on Family Resources, Child Survival and Reproductive Health, Cairo. 1988.

[8] "Measuring Reproductive Morbidity", Report of a Technical Working Group, World Health Organization. Geneva. 1989
[9] Bhatnagar N, Khandekar J, Singh A, Saxena S."The silent epidemic of reproductive morbidity among ever married women (15-49 years) in an urban area of Delhi”.J Community Health. 2013 Apr;38(2):250-6.

[10] M.C., Foreman K.J., Naghavi M., Ahn S. Y., Wang M., Makela S.M., Lopez A.D., Lozano R., Murray C.J.L. "Maternal mortality for 181 countries, 1980-2008: A Systematic Analysis of Progress towards Millennium Development Goal 5. The Lancet. 2010;375(9726):1609-1623.

[11] WHO, UNICEF, UNFPA, and the World Bank. "Trends in maternal mortality: 1990 to 2008. Geneva: WHO; 2010".

\section{Author Profile}

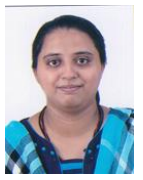

Dr. Firdous Ansari received Doctor of Philosophy (Ph.D.) degree in Statistics in the year 2012 from Singhania University Jhunjhunu, Rajasthan. She did her Ph.D. work at Desert Medicine Research Centre,Jodhpur(Indian Council of Medical Research (ICMR)New Delhi) under the guidance of Dr. Ashutosh Kumar Dixit, Scientist „F“ and Head of the Bio-statistics Divison, DMRC, Jodhpur, Rajasthan.. Ansari got her Master degree in Statistics from Jai NarainVyas University in the year 2006. She is Gold Medallist of her batch. She has an experience of teaching of about two years (2010-2012) as a Research Associate at Banasthali University, Niwai, Jaipur, Rajasthan. She also provided her services as Assistant Professor in the Department of Mathematics and Statistics, Jai NarainVyas University ,Jodhpur for a duration of about two years (2013-2015). 